\title{
DUBET, François. O que é uma escola justa? - A escola das oportunidades. São Paulo: Cortez, 2008.
}

\section{Por Waldirene Sawozuk Bellardo}

Ao final da primeira década do século XXI vivemos uma conjuntura política ímpar no terreno da educação - forjada pela correlação de forças entre a sociedade política e a sociedade civil organizada - que culminou na Conferência Nacional de Educação (CONAE) e no atual Projeto de Lei 8035/2010 que tramita no Congresso Nacional.

Esse movimento, ao deflagrar o processo de elaboração e aprovação do novo Plano Nacional de Educação, reacende as discussões acerca de um projeto de escola mais justa, especialmente quando confrontado com a perpetuação secular de nossos dois maiores problemas educacionais: o analfabetismo e a inacessibilidade à educação básica.

Nesse contexto, a possibilidade de interferir nos rumos da educação de nosso país - via acompanhamento e proposição de emendas ao PL 8035/2010 - nos mobiliza a repensar os contornos da escola que queremos: consensualmente adjetivada de [mais] justa e igualitária.

Não obstante, propor o desenho de uma escola sob o crivo da Justiça e da Igualdade, numa sociedade marcadamente desigual, pode caracterizar certo nível de ingenuidade e ilusão.

Desse modo, para não criar simulacros que imobilizem a realização do possível hoje - ainda que nos limites da sociedade capitalista - é que torna-se indispensável a leitura desta obra de Dubet, cujo movimento é desencadear, sob a égide da justiça e da igualdade, políticas possíveis para que [no contexto específico do livro] a escola francesa aproxime-se mais do princípio meritocrático da igualdade das oportunidades.

Para tanto, François Dubet inicia sua obra explicitando o propósito deste ensaio: definir o que poderia ser uma escola justa; ou, nas palavras do autor, "uma escola o menos injusta possível." (DUBET, 2008, p.9) Ao debruçar-se sobre o tema, o sociólogo francês - professor da Universidade de Bordeaux 2 e diretor adjunto do Centro de Análise e de Intervenção Sociológica (Cadis), da École des Hautes Études em Sciences Sociales em Paris - imprime à obra um conceito de Justiça que supera sua faceta metaética, pois a confronta, empiricamente, com o modelo educativo francês, perscrutando-o sob os auspícios da implantação do princípio da igualdade das oportunidades.

Tal postura científica reitera a preocupação do escritor, já presente em outras obras traduzidas para o português ${ }^{1}$, de reafirmar o papel da sociologia na explicitação clara e crítica dos problemas sociais e na busca de sua superação. Segundo Dubet "repensar a justiça da escola é ir à procura de novas articulações entre princípios e realidades" (DUBET, 2008, p.9, sem grifos no original).

Com tal assertividade é que, François Dubet, em "O que é uma escola justa?", recoloca em discussão, já no primeiro capítulo do livro, debates primevos que permanecem inconclusos, (re)articulando princípios como os de justiça e igualdade e o modo como eles se forjam e são forjados no ambiente escolar.

A atualidade e densidade desse debate é condição sine qua non para pensar políticas educacionais que, além de ampliar as demandas emergentes de acesso, também respondam às demandas relativas à permanência e qualidade da educação escolar. Nesse sentido, Dubet não é o único a destacar a indissociabilidade entre os

1 DUBET, François. As desigualdades multiplicadas. Ijuí: Ed. Unijuí, 2003. 
princípios de justiça e igualdade. Norberto Bobbio também afirma quea "igualdade e ajustiça possuem, na realidade, uma importante característica comum: ambas só podem ser sustentadas por regras que determinam como certos benefícios ou gravames hão de ser distribuídos entre as pessoas." (BOBBIO, 2010, p.598).

Essas regras são desveladas por Dubet nesta obra, especialmente quando o autor demonstra o imbricamento existente entre a constituição de sociedades modernas democráticas e o princípio da igualdade das oportunidades e da valorização do mérito; tal pressuposto permite "conciliar dois princípios fundamentais: de um lado, o da igualdade entre os indivíduos; do outro, o da divisão do trabalho necessário a todas as sociedades modernas." (.BUBET, 2008, p. 19) É nesta direção que se institui o consenso de que a igualdade das oportunidades delineia um modelo mais justo de escola, pois as desigualdades que se constroem refletem, supostamente, a competência e a capacidade individual de cada um.

Destarte, o livro desmascara a lógica capitalista que reduz a igualdade a uma pseudo-neutralidade, omitindo os elementos fundantes da desigualdade pela prática compulsória da meritocracia.

É assim que "(...) a igualdade meritocrática das oportunidades permanece a figura cardinal da justiça escolar. Ela designa o modelo de justiça, permitindo a cada um concorrer numa mesma competição sem que as desigualdades da riqueza e do nascimento determinem diretamente suas oportunidades de sucesso e de acesso a qualificações escolares relativamente raras. (DUBET, 2008, p. 11) Cria-se, no bojo desse constructo, a ficção necessária às sociedades democráticas modernas, capaz de justificar as diferenças de remuneração, prestígio, poder e, especialmente, de performance escolar.

Contrariamente, desenhar contornos mais poliárquicos dos princípios de justiça escolar esbarra, segundo o autor, numa dificuldade empírica que engendra o modelo da igualdade das oportunidades, pois "esse modelo nunca foi totalmente realizado" haja vista a impossibilidade de neutralizar o sistema escolar dos efeitos decorrentes das desigualdades sociais em suas múltiplas facetas. (DUBET, 2008, p. 11)
É nesse contexto, recheado de antagonismos, que desloca-se o esforço necessário para construir uma escola mais justa que amplie o conceito de igualdade sem, no entanto, prescindir o modelo de igualdade das oportunidades. Mais do que renunciar a este modelo - fato que traria perdas históricas à educação das massas - é preciso ampliá-lo.

Para validar tal premissa Dubet retrata episódios do modelo escolar francês destacando, especialmente, as mudanças decorrentes da passagem de uma concepção denominada de elitismo republicano ao pressuposto da igualdade das oportunidades, referenciando empiricamente o plano Langevin-Wallon. Segundo o sociólogo, nesse período, começa a constituir-se, na França, um modelo escolar em que somente o mérito e o talento individual poderiam justificar possíveis desigualdades escolares; "uma sociedade na qual as desigualdades procedam unicamente do mérito e das performances pessoais." (DUBET, 2008, p.24)

Essa 'revolução' no sistema escolar francês imprimiu uma democratização quantitativa (acesso) incontestável; mas, concomitantemente, também explicitou outros obstáculos à igualdade das oportunidades, mais difíceis de combater por estarem visceralmente arraigados à sociedade de classes.

"Os alunos são colocados no centro de uma contradição fundamental: todos eles são considerados fundamentalmente iguais por estarem todos engajados numa série de provações cuja finalidade é torná-los desiguais. (...) Assim, o aluno que fracassa aparece como o responsável pelo seu próprio fracasso e, ao mesmo tempo, sua igualdade fundamental é preservada, pois tudo se passa como se ele tivesse decidido "livremente" sobre suas performances escolares trabalhando mais ou menos." (DUBET, 2008, p.40-41)

Por isso, a pugna do autor é elucidar as contradições do mérito como expressão de um modelo escolar consubstanciado no princípio da igualdade das oportunidades. Para tanto, paradoxalmente, ele "aceita" e questiona o mérito: "não se pode ignorar que as provações do mérito, mesmo justas, são de uma grande crueldade para os que fracassam, principalmente quando esse 
fracasso énecessário ao funcionamento do mérito e da igualdade das oportunidades. Entretanto, seria muito difícil imaginar um princípio de justiça escolar alternativo à igualdade meritocrática e tão forte quanto ela." (DUBET, 2008, p. 47)

Portanto, ao questionar o mérito e seu impacto na vida escolar e social dos indivíduos, o ensaio de Dubet não nega o princípio da igualdade das oportunidades, ao contrário, intenta ampliar seu alcance, como já foi destacado anteriormente, refletindo diretamente sobre os meios de dela se aproximar.

Essa aproximação mais concreta e ampliada ao princípio da igualdade das oportunidades foi desenvolvida, nesse livro, em três dos quatro capítulos da obra.

No capítulo II, denominado "A igualdade distributiva das oportunidades", o sociólogo francês subverte a ficção necessária da igualdade das oportunidades para as sociedades democráticas, acrescendo-lhes uma nova sensibilidade: a da igualdade dos resultados e de suas implicações na gestão escolar. Nesse ínterim, descreve as vicissitudes do mapa escolar ${ }^{2}$, bem como os diversos mecanismos intra e extra-escolares utilizados para burlá-lo.

Descritos tais aspectos do sistema escolar francês, a centralidade desse capítulo recai sobre o conceito de equidade, definido politicamente como "dar mais e, sobretudo, melhor, aos que têm menos." (DUBET, 2008, p.60) As ações que se encaminham nessa direção são chamadas pelo autor de discriminação positiva. No Brasil, há políticas similares conhecidas como 'ações afirmativas'; mas, na França, aponta-se para que a discriminação positiva incida sobre os sujeitos individualmente. "A discriminação positiva deve ser defendida com a condição de que sirva para apontar indivíduos e não coletivos, pois é no nível de cada indivíduo que se cristalizam verdadeiramente os handicaps $e$ as desigualdades sociais." (DUBET, 2008, p. 62)

Aindanessecapítulo, há descrições significativas acerca da importância das informações e da

2 A política francesa do mapa escolar tem seu equivalente, no Estado do Paraná, denominado de georreferenciamento. Trata-se de um sistema da Secretaria de Estado da Educação que consiste em encaminhar os alunos da rede pública à escola estadual mais próxima de sua residência. mobilidade intra-escolar (conhecimento das regras e dos códigos escolares, explícitos ou não) como condição indelével de sucesso. "A desigualdade das oportunidades não se deve apenas às desigualdades de remuneração dos indivíduos e aos diferenciais de qualidade da oferta escolar, ela procede também das competências dos pais que sabem utilizar relativamente bem essa oferta" (DUBET, 2008, p. 64-65)

Explicitadas as diferentes facetas das desigualdades escolares 0 autor insiste na necessidade de se formular políticas de discriminação positiva, voltadas tanto aos indivíduos quanto às instituições escolares mais frágeis.

Na sequência, além da igualdade distributiva, Dubettratad"Aigualdadesocial dasoportunidades", título do capítulo III, que tem como tema central o pressuposto de que "a equidade de um sistema escolar pode também ser julgada pela maneira como os mais fracos são tratados" (DUBET, 2008, p.13), ou seja, "as desigualdades engendradas por uma competição equitativa e aberta para acessar recursos e vagas são aceitáveis desde que não degradem ainda mais a condição dos menos favorecidos." (DUBET, 2008, p. 73) Trata-se, portanto, de questionar não somente o modelo de justiça construído sob o imperativo do mérito, mas também de considerar "outras figuras da justiça", dentre elas, a apropriação por todos, e cada um, dos bens escolares: ressalta-se o princípio da garantia de um limiar mínimo de aprendizagem a ser acessado por todos os indivíduos, independente de sua performance escolar, denominado na obra de "SMIC ${ }^{3}$ escolar".

Sem atacar o princípio do mérito, convém garantir a todos os alunos a aquisição da cultura comum a que têm direito. Ao lado de uma igualdade das oportunidades que deve possibilitar aos melhores alcançarem a excelência, é preciso definir o que a escola obrigatória deve obrigatoriamente garantir a todos os alunos (DUBET, 2008, p. 75).

Todavia, há fortes resistências ao "SMIC escolar" impulsionadas pelo receio de

3 SMIC - Salário Mínimo Interprofissional de Crescimento. "Significa que as desigualdades de salários são toleráveis desde que não afetem o salário mínimo, abaixo do qual legalmente não é possível descer." (DUBET, 2008, p. 73). 
transformação do mínimo em máximo, ainda que não se abandone a ideia de um bem comum disponibilizado a todos, e a cada um, pela escola.

Prosseguindo, Dubet discute exatamente as dificuldades em se definir, objetivamente, essa cultura comum; e, embora não se arrisque em fazêlo, aponta pressupostos importantes que subjazem tal conceito, explicitando seu caráter eminentemente político. "Essa escolha não é somente técnica: ela decorre de decisões e de princípios que excedem, e muito, a pedagogia." (DUBET, 200, p. 81) Priorizar a igualdade social das oportunidades "introduzirá certamente uma mutação tão radical quanto o fora a extensão dos direitos sociais, dando, ao preço de muitas lutas, alguma "realidade" aos direitos políticos." (DUBET, 2008, p. 93)

No último capítulo "A igualdade individual das oportunidades" aborda-se o efeito das desigualdades escolares sobre as desigualdades sociais, tendo como pivô o diploma escolar: sua utilidade $^{4}$ e hierarquização. Assim, embora seja necessário acreditar na ficção da igualdade meritocrática das oportunidades e, portanto, na produção de desigualdades mais ou menos justas no interior de cada esfera de atividade - dentre elas a educação - quando tais desigualdades extrapolam o âmbito de seu domínio gerando desigualdades em outras esferas da vida humana, têm-se claramente um caso de injustiça e dominação. A esse respeito, o autor faz menção a um estudo comparativo entre as estruturas escolares e profissionais da França e da Alemanha, concluindo que "a estrutura do sistema escolar e a das desigualdades que ele engendra têm consequências não negligenciáveis sobre as desigualdades sociais e a mobilidade dos indivíduos no curso de sua vida profissional." (DUBET, 2008, p. 99)

Destarte, o princípio da igualdade individual das oportunidades tem como horizonte a construção de uma sociedade mais democrática e solidária sob a qual a educação permitirá a "cada um ser um sujeito independentemente de seu mérito e das utilidades ligadas aos diplomas" (DUBET, 2008, p. 110), cujo objetivo maior será

4 Dubet concebe a utilidade dos diplomas pela "quantidade de bens que eles permitem adquirir em termos de estatuto, de remuneração, de proteção, de prestígio..." (DUBET, 2008, p. 97) o de preservar os indivíduos de uma espécie de "darwinismo social".

Em suas conclusões, Dubet reafirma a urgência da reforma escolar a partir de ações políticas que considerem a igualdade distributiva, social e individual em detrimento ao conceito monolítico de justiça imbricado a igualdade meritocrática das oportunidades - suporte da escola republicana francesa. Não obstante, em nenhum momento o autor assume uma postura ingênua relativa às necessárias transformações escolares, ao contrário, expõe com propriedade e discernimento as dificuldades inerentes a esse processo de mudança, caracterizando o espaço escolar como um "terreno de lutas extremamente ferozes no qual os grupos que conseguem se sair bem não estão dispostos a correr o risco de mudar as regras." (DUBET, 2008, p. 118).

Tal postura decorre do fato de que as mudanças desejadas são pensadas sob o crivo do Estado Moderno de Direito, portanto, sob um Estado capitalista que tem sua gênese articulada à constituição das classes sociais; mas, também este Estado, como defende Poulantzas, é um espaço de disputa - ainda que desigual - entre forças contraditórias e antagônicas. Assim, é neste cenário, de disputas possíveis e crescentes, no interior de uma sociedade real e contraditória, que se inscrevem os pressupostos desse ensaio. Nas palavras do autor "a ambição deste livro é menos convencer da excelência de suas respostas do que da urgência de seus questionamentos" (DUBET, 2008, p. 119).

Urge, assim, desmistificar a afirmação propagada pelo liberalismo clássico de que a igualdade de oportunidades é possível mediante a garantia, para todos, da vida, da liberdade e da propriedade privada, cabendo a cada um percorrer o caminho necessário ao alcance de uma posição social apropriada à sua máxima capacidade. O ensaio "O que é uma escola justa?" do sociólogo François Dubet, faz esse movimento: mobiliza os diferentes atores sociais a não abandonarem o combate por uma escola mais justa, fazendo-o por meio de uma leitura crítica e rigorosa da realidade. 